Revista Destaques Acadêmicos, Lajeado, v. 9, n. 1, 2017. ISSN 2176-3070 DOI: http://dx.doi.org/10.22410/issn.2176-3070.v9i1a2017.1258 www.univates.br/revistas

\title{
ANÁLISE DO PERFIL DO PROFISSIONAL CONTÁBIL REQUERIDO PELAS EMPRESAS DO VALE DO TAQUARI-RS
}

\author{
Ana Paula Biasibetti ${ }^{1}$, Alexandre André Feil ${ }^{2}$
}

Resumo: A temática deste estudo centra-se no perfil do profissional contábil na visão das organizações. A problemática relaciona-se em responder qual o perfil do profissional contábil requisitado pelo mercado de trabalho pelas empresas do Vale do Taquari-RS. A metodologia empregada quanto a abordagem é qualitativa e quantitativa e tipificada em pesquisa descritiva e survey. A survey ocorreu por meio da aplicação de questionário misto em 105 empresas, destas, retornaram 43 respondidos. Os principais resultados revelam que as empresas preferem contratar profissionais contábeis com idade de 26 até 35 anos, de 4 até 5 anos de experiência, saibam falar a língua alemã, graduação em Ciências Contábeis, trabalhar em equipe e que tenham comprometimento com o seu trabalho e domínio nas áreas. Conclui-se que o profissional contábil requisitado pelo mercado de trabalho deve ter conhecimento e experiência prévia na área contábil, além disso, amplo conjunto de competências e habilidades.

Palavras-chave: Escrituração contábil interna. Competência. Habilidades. Mercado de Trabalho.

\section{INTRODUÇÃO}

O profissional contábil, na atualidade, deve se preparar para um mercado que possui influências de uma cultura globalizada (MARIN; LIMA; NOVA, 2014). A contabilidade possui vínculos nos aspectos comportamentais das empresas, exigindo uma nova postura dos profissionais inseridos no mercado de trabalho (SILVEIRA, 2013).

As empresas buscam profissionais eficazes que estejam preparados para atuar no mercado de trabalho, que sejam criativos, íntegros, éticos, visão futurista, habilidade de negociação, ágeis, seguros para resolver problemas,

1 Bacharel em Ciências contábeis pelo Centro Universitário UNIVATES.

2 Doutor em Qualidade Ambiental pela Universidade Feevale, Docente adjunto do Centro de Gestão Organizacional vinculado ao curso de Ciências Contábeis. 
capacidades de aprender a lidar com as mudanças, ideias de melhorias, flexíveis, inovadores, entre outros (TEIXEIRA; ALVES, 2014).

O profissional contábil, considerando os diversos campos profissionais, tem a seu dispor um dos maiores mercados, pois nenhuma empresa e instituição pode dispensar sua assistência constante (SÁ, 2006). Na profissão contábil, assim como em qualquer profissão, existem algumas vantagens e desvantagens. A contratação de um profissional contábil eficaz propicia vantagens para a empresa, tais como melhorias nos custos, tributos e auxiliar na tomada de decisões (ECKERT, 2014). As desvantagens podem ser os custos com sua contratação, refletindo que optem pela contabilidade externa ao invés da interna (DIEHL, 2010). Com o crescimento do mercado de trabalho, aumentam as oportunidades de emprego; e por sua vez, as empresas têm demudado seus conceitos na contratação de profissionais contábeis (FERREIRA, 2013).

$\mathrm{O}$ atendimento da expectativas da sociedade moderna, em relação aos profissionais contábeis qualificados, também necessita um repensar das Instituições de Ensino Superior (IES) (RODRIGUES, 2009). Neste sentido, as IES devem oferecer os meios e recursos para formar cidadãos conscientes de seus direitos e deveres, para que se tornem profissionais eficazes em suas áreas de atuação. As Diretrizes Curriculares Nacionais se constituem em orientações para a elaboração dos currículos a serem respeitadas por todas as IES e asseguram a flexibilidade e a qualidade da formação oferecida aos estudantes (CASNOK; POLLI; POLLI, 2005).

Neste contexto, a problemática deste estudo é qual o perfil do profissional contábil requisitado pelo mercado de trabalho? No alcance da solução deste problema tem-se como objetivo geral analisar o perfil do profissional contábil que as empresas desejam no Vale do Taquari - RS. Os objetivos específicos relacionam-se: a) analisar o perfil socioeconômico desejado; b) analisar as principais características do perfil do profissional contábil frente às empresas; c) Verificar quais são os requisitos laborais que o mercado de trabalho requer do profissional contábil; e d) Apurar o perfil que o mercado de trabalho requer dos profissionais contábeis. A justificativa centra-se pela relevância do tema na área contábil.

\section{REFERENCIAL TEÓRICO}

\subsection{Os profissionais da contabilidade e o mercado}

O profissional da Contabilidade tem sua profissão regulamentada pelo Decreto-lei $n^{\circ}$ 9.295/46 e suas atribuições definidas pela Resolução $n^{\circ}$ 560/83, do Conselho Federal de Contabilidade (CFC), que dispõe sobre as prerrogativas profissionais da área. $\mathrm{O}$ art. $\mathrm{n}^{\circ} 2$ dessa resolução define as atividades que os profissionais contábeis podem exercer e se especializar em vários ramos: 
O contabilista pode exercer as suas atividades na condição de profissional liberal ou autônomo, de empregado regido pela CLT, de servidor público, de militar, de sócio de qualquer tipo de sociedade, de diretor ou de conselheiro de quaisquer entidades, ou, em qualquer outra situação jurídica definida pela legislação, exercendo qualquer tipo de função. Essas funções poderão ser as de analista, assessor, assistente, auditor, interno e externo, conselheiro, consultor, controlador de arrecadação, controller, educador, escritor ou articulista técnico, escriturador contábil ou fiscal, executor subordinado, fiscal de tributos, legislador, organizador, perito, pesquisador, planejador, professor ou conferencista, redator, revisor.

Essas funções poderão ser exercidas em cargos como os de chefe, subchefe, diretor, responsável, encarregado, supervisor, superintendente, gerente, subgerente, de todas as unidades administrativas onde se processem serviços contábeis. Quanto à titulação, poderá ser de contador, contador de custos, contador departamental, contador de filial, contador fazendário, contador fiscal, contador geral, contador industrial, contador patrimonial, contador público, contador revisor, contador seccional ou setorial, contadoria, técnico em contabilidade, departamento, setor, ou outras semelhantes, expressand o o seu trabalho através de aulas, balancetes, balanços, cálculos e suas memórias, certificados, conferências, demonstrações, laudos periciais, judiciais e extrajudiciais, levantamentos, livros ou teses científicas, livros ou folhas ou fichas escriturados, mapas ou planilhas preenchidas, papéis de trabalho, pareceres, planos de organização ou reorganização, com textos, organogramas, fluxogramas, cronogramas e outros recursos técnicos semelhantes, prestações de contas, projetos, relatórios, e todas as demais formas de expressão, de acordo com as circunstâncias.

O mercado de trabalho da área contábil é amplo e oferece diversas oportunidades para uma carreira bem-sucedida. Atualmente, a profissão vive um momento áureo, pois onde há uma empresa - pequeno, médio ou grande porte - existe um profissional contábil (CACERE; CARDOSO; NORONHA, 2008). Cruz, Andrich e Schier (2011) ainda destacam que a contabilidade é uma das áreas que mais proporcionam oportunidades de emprego para os profissionais. Entre estas profissões destacam-se o docente, sendo este um pilar essencial na qualificação do profissional contábil.

Peleias (2006, p. 130), salienta que no processo do ensino,

[...] o professor é o fator intrínseco do processo de ensinoaprendizagem, atuando como facilitador e fortalecendo a autonomia dos alunos na aprendizagem, pelo estímulo ao desenvolvimento da capacidade crítica, da criatividade e da iniciativa. O professor precisa usar estratégicas didáticas que ponham o aluno em contato com elementos culturais distantes do seu cotidiano e que, ao mesmo 
tempo, implicam uma ação consciente e transformadora em relação aos ambientes de trabalho e comunidades em que ele atuará ou em que já está inserido.

Além deste exemplo, destaca-se o papel do profissional contábil público, pois para Brandalise, Fella e Zamin $(2009$, p. 3) deve:

[...] buscar sempre na execução de seus trabalhos a transparência dos demonstrativos contábeis e financeiros, para que todos os cidadãos tenham compreensão das ações de seus governantes, aguçando assim a análise crítica e permitindo entendimento das formas de atuação dos mesmos, especialmente quando diz respeito à subtração de parte do patrimônio da população por meio de tributos.

O profissional contábil também possui um papel relevante na gestão pública, auxiliando nos projetos financeiros de investimentos em melhorias de obras públicas, gastos com salários, taxas e outros, acompanhando o sistema orçamentário para que não ultrapasse o limite previsto dos desembolsos e, consequentemente, desfalque os cofres públicos (SILVA, 2012).

Alberto (1996, p. 48) explica que o profissional independente na "[...] função do perito é pertinente, visto que as opiniões são de exclusiva competência do perito. Seu trabalho é extremamente zeloso devido a sua confiabilidade nos serviços prestados". Além disso, enfatiza (p. 48) que a auditoria "[...] é uma das áreas de atuação à qual compete a verificação da exatidão das informações contábeis e financeiras, tendo objetivo de avaliar os procedimentos: contábil, financeiro e estoque na organização".

Nas empresas, o profissional contábil participa do processo de gestão, interage com outros grupos, além de coletar e gerenciar as informações contábeis, para que as tomadas de decisões sejam precisas (SILVA, 2012). Silva (2015) afirma que quase todas as áreas do conhecimento utilizam a contabilidade como fonte de dados, destarte percebe-se a importância da contabilidade para a sociedade empresarial.

\subsection{Competências, habilidades e conhecimentos do profissional contábil}

A competência é entendida como a capacidade de algo ou alguém para realizar determinada função com sucesso (FLEURY; FLEURY, 2001). Cardoso (2006) expõe que na Contabilidade os estudos relativos às competências confundem-se em parte com as funções e as atividades propostas ao profissional contábil. Além disso, observou que a literatura geralmente aborda a função dos profissionais contábeis ao invés das competências. Dessa forma, realizou um levantamento indicando as principais competências do profissional contábil moderno e globalizado (QUADRO 1). 
Quadro 1 - Competências do profissional contábil

\begin{tabular}{|c|c|}
\hline Competências & Descrição \\
\hline Analítica & $\begin{array}{l}\text { Sabe analisar as partes de um problema ou situação estabelecendo } \\
\text { suas relações para formular diversas soluções e o valor de cada um. }\end{array}$ \\
\hline Autocontrole & $\begin{array}{l}\text { Mantém o desempenho sob condições estressantes e hostis, } \\
\text { respondendo positivamente aos problemas sem impulsividade e } \\
\text { permanecendo calmo. }\end{array}$ \\
\hline Comunicação & $\begin{array}{l}\text { Estabelece sintonia nas comunicações com pessoas ou grupos, } \\
\text { entende mensagens e é entendido. Demonstra boa articulação ao } \\
\text { comunicar ideias por escrito e verbalmente. }\end{array}$ \\
\hline Empreendedor & $\begin{array}{l}\text { Desenvolve soluções criativas para os problemas da empresa e dos } \\
\text { clientes; procura inovar diante das restrições da empresa. Assume } \\
\text { riscos calculados. }\end{array}$ \\
\hline Estratégia & $\begin{array}{l}\text { Compreende o que está acontecendo no mercado e em sua empresa. } \\
\text { Entende, antecipa e procura responder além das necessidades dos } \\
\text { consumidores no longo prazo. }\end{array}$ \\
\hline $\begin{array}{l}\text { Ferramentas de } \\
\text { Controle }\end{array}$ & $\begin{array}{l}\text { Conhece e utiliza as ferramentas de controle e gestão, como } \\
\text { orçamento, controle interno, custos, fluxo de controle de caixa, } \\
\text { entre outros. }\end{array}$ \\
\hline Legal & $\begin{array}{l}\text { Conhece e acompanha tarefas obrigatórias, como planejamento } \\
\text { tributário e atendimento das exigências fiscais. }\end{array}$ \\
\hline Informática & $\begin{array}{l}\text { Conhece e utiliza a informática como ferramenta na identificação, } \\
\text { seleção e formatação de informações gerenciais para o processo } \\
\text { decisório. }\end{array}$ \\
\hline $\begin{array}{l}\text { Integridade e } \\
\text { Confiança }\end{array}$ & $\begin{array}{l}\text { Tem integridade e exprime positivamente seus valores e crenças } \\
\text { pessoais de maneira consistente com os padrões éticos de sua } \\
\text { empresa. Inspira confiança pelo cumprimento dos compromissos } \\
\text { assumidos. }\end{array}$ \\
\hline $\begin{array}{l}\text { Contabilidade e } \\
\text { finanças }\end{array}$ & $\begin{array}{l}\text { Domina e interpreta os conceitos relacionados à área de } \\
\text { contabilidade e finanças empresariais, atendendo aos interesses } \\
\text { dos usuários internos e externos dessa informação e das normas } \\
\text { vigentes tanto no ambiente nacional como no internacional. }\end{array}$ \\
\hline Negociação & $\begin{array}{l}\text { Realiza acordos com as várias áreas envolvidas com o sistema de } \\
\text { informação e mensuração de desempenho, adicionando valor e } \\
\text { vantagens competitivas às negociações. Busca opções para atender } \\
\text { aos interesses dos envolvidos e da empresa. }\end{array}$ \\
\hline $\begin{array}{c}\text { Ouvir } \\
\text { eficazmente }\end{array}$ & $\begin{array}{l}\text { Desenvolve diálogos interativos com as pessoas, pergunta por mais } \\
\text { detalhes sobre os assuntos, avalia as mensagens e fornece feedback. }\end{array}$ \\
\hline Atendimento & $\begin{array}{l}\text { Sabe atender e dialogar, demonstrando corretamente os conceitos e } \\
\text { critérios utilizados nos sistemas de informação, tanto para usuários } \\
\text { internos à empresa como para auditores externos, fornecedores, } \\
\text { mercado de capital e instituições financeiras. }\end{array}$ \\
\hline
\end{tabular}




\begin{tabular}{|c|c|}
\hline Competências & Descrição \\
\hline Planejamento & $\begin{array}{l}\text { Estuda e aplica conceitos de planejamento e acompanhamento } \\
\text { estratégico, operacional e financeiro, auxiliando a alta administração } \\
\text { no alcance de seus objetivos. }\end{array}$ \\
\hline $\begin{array}{l}\text { Técnica de } \\
\text { Gestão }\end{array}$ & $\begin{array}{l}\text { Demonstra estar atualizado com técnicas, dados e novos } \\
\text { conhecimentos por meio de leitura, cursos, viagens, congressos, etc. }\end{array}$ \\
\hline $\begin{array}{l}\text { Trabalho em } \\
\text { Equipe }\end{array}$ & $\begin{array}{l}\text { Coopera com demais membros da equipe, com cujas metas e } \\
\text { objetivos é comprometido. Compreende e esforça-se para o bem da } \\
\text { equipe em vez de servir aos próprios interesses. }\end{array}$ \\
\hline $\begin{array}{l}\text { Gestão da } \\
\text { Informação }\end{array}$ & $\begin{array}{l}\text { Capacidade de gerenciar todas as informações necessárias para o } \\
\text { bom andamento dos negócios, efetuando melhorias e supervisão } \\
\text { no sistema de processamento de dados e interagindo com áreas } \\
\text { correlatas, como Tecnologia de Informações (TI). }\end{array}$ \\
\hline $\begin{array}{l}\text { Relacionamento } \\
\text { Externo }\end{array}$ & $\begin{array}{l}\text { Realiza acordos e negociação com instituições financeiras, órgãos } \\
\text { governamentais, fornecedores, acionistas, clientes e empregados, } \\
\text { buscando atender aos interesses da empresa. }\end{array}$ \\
\hline
\end{tabular}

Fonte: Adaptado de Cardoso (2006).

O profissional contábil desenvolve o seu conceito através de meios competentes e honestos, visto que, além do reconhecimento de suas virtudes e capacidade de exercer um bom trabalho e com qualidade, esse profissional deve seguir um conjunto de princípios éticos, que servem de base para o cumprimento de suas funções (SÁ, 2006).

O desenvolvimento de "[...] habilidades e competências necessita ser visto em si como objetivo de ensino. Competência é mais do que um conhecimento, ela pode ser explicada como um saber que se traduz na tomada de decisões, na capacidade de avaliar e julgar" (SILVA, 2015, p. 10). Chiavenato (2000, p. 166) salienta que os indivíduos possuem pelo menos uma competência básica "[...] na forma de conhecimentos, habilidades, atitudes, interesses, traços valor ou outra característica pessoal - são aquelas características pessoais essenciais para o desempenho da atividade e que diferenciam o desempenho das pessoas". Vieira (2002) explica que a competência tem três dimensões: conhecimento, habilidade e atitudes, englobando as questões técnicas e cognição necessárias à execução de um determinado trabalho (FIGURA 1). 
Figura 1 - Conjunto de potencialidade

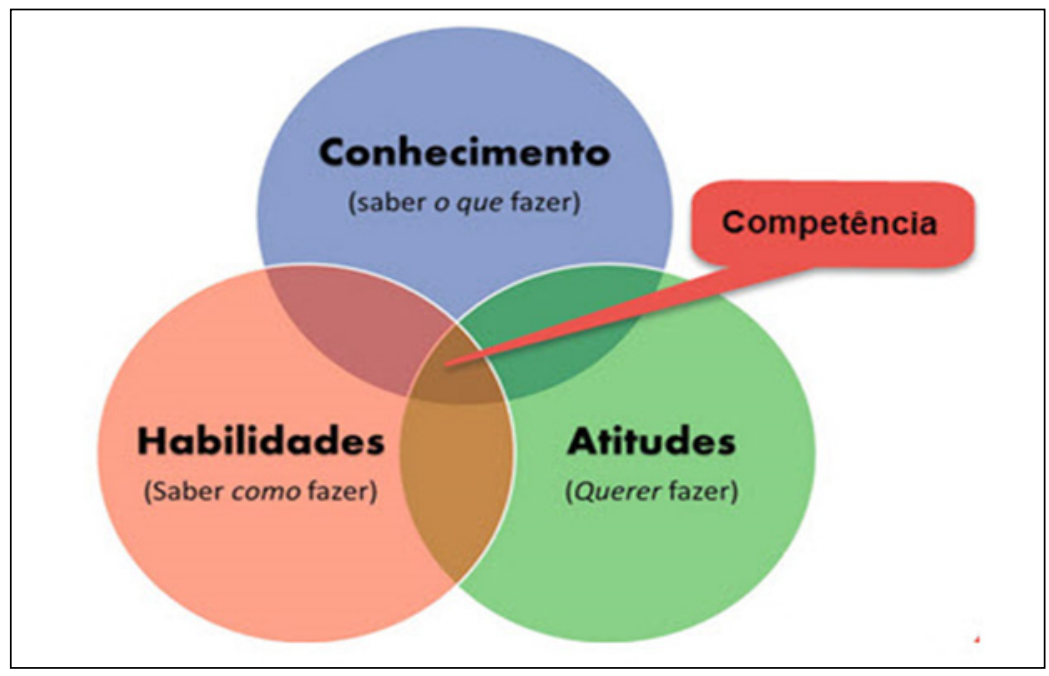

Fonte: Adaptado de Vieira (2002).

Com base neste conjunto de potencialidades Fernandes e Antunes (2010) estratificam os principais tipos de habilidades, conhecimentos e competências e suas definições (QUADRO 2).

Quadro 2 - Habilidades, conhecimentos e competências

\begin{tabular}{|c|c|}
\hline Habilidades & Definições \\
\hline Interpessoais & $\begin{array}{l}\text { Pensamento lógico, raciocínio dedutivo e indutivo, habilidade em } \\
\text { identificar e resolver problemas, habilidades de atribuir prioridades } \\
\text { dentro dos recursos restritos. }\end{array}$ \\
\hline Interpessoais & $\begin{array}{l}\text { Habilidade de interagir com pessoas de cultura diferente, resolver } \\
\text { conflitos, habilidades em trabalhos de grupo, motivação. }\end{array}$ \\
\hline Comunicação & $\begin{array}{l}\text { Capacidade de ouvir, comunicação interpessoal e dinâmica de grupo, } \\
\text { habilidade de apresentação oral, idiomas estrangeiros. }\end{array}$ \\
\hline Conhecimentos & Definições \\
\hline Gerais & $\begin{array}{l}\text { Conhecimentos básicos sobre economia, matemática, estatística e } \\
\text { psicologia. Compreende as ideias dos eventos e as culturas diferentes } \\
\text { no mundo atual. }\end{array}$ \\
\hline Organizacionais & $\begin{array}{l}\text { Ter conhecimento dos negócios, das atividades desenvolvidas na } \\
\text { empresa, do governo e do ambiente em que operam, conhecimentos } \\
\text { básicos sobre finanças dos instrumentos financeiros e dos mercados } \\
\text { importantes, ter noção sobre métodos para criar controlar as } \\
\text { mudanças nas organizações. }\end{array}$ \\
\hline Área Contábil & $\begin{array}{l}\text { Conhecimentos de sistemas de informação, regulamentos da } \\
\text { contabilidade nacional e internacional, identificação, mensuração, } \\
\text { recolher e analisar dados financeiros, conhecimentos de auditoria, } \\
\text { conhecimentos de contabilidade internacional. }\end{array}$ \\
\hline
\end{tabular}




\begin{tabular}{|c|l|}
\hline Competências & \multicolumn{1}{c|}{ Definições } \\
\hline Gerais & $\begin{array}{l}\text { Envolvem conhecer e entender as correntes econômicas, políticas, } \\
\text { sociais e culturas de uma forma global. }\end{array}$ \\
\hline Comerciais & $\begin{array}{l}\text { Refere-se ao conhecimento do segmento de mercado em que se esteja } \\
\text { atuando. }\end{array}$ \\
\hline Organizacionais & $\begin{array}{l}\text { Conhecimento do processo operacional da organização em sua área } \\
\text { de atuação, através do conhecimento e interação entre o mercado e o } \\
\text { grupo organizacional. }\end{array}$ \\
\hline Técnicas & $\begin{array}{l}\text { Conhecimento das normas e princípios contábeis, ser capaz de } \\
\text { desenvolver, analisar e implantar sistemas de informações contábeis } \\
\text { e de controle gerencial. }\end{array}$ \\
\hline
\end{tabular}

Fonte: Adaptado de Fernandes e Antunes (2010).

Reis et al. (2014) defendem que no desempenho do profissional contábil é essencial o desenvolvimento de habilidade e competência, além dos conhecimentos teóricos. A resolução CNE/CES de 2004 determina que o curso de Ciências Contábeis deve possibilitar uma formação profissional que revele, no mínimo, as seguintes habilidades e competências:

I - Utilizar adequadamente a terminologia e a linguagem das Ciências Contábeis e Atuariais;

II - Demonstrar visão sistêmica e interdisciplinar da atividade contábil;

III - elaborar pareceres e relatórios que contribuam para o desempenho eficiente e eficaz de seus usuários, quaisquer que sejam os modelos organizacionais;

IV - Aplicar adequadamente a legislação inerente às funções contábeis;

$\mathrm{V}$ - Desenvolver, com motivação e através de permanente articulação, a liderança entre equipes multidisciplinares para a captação de insumos necessários aos controles técnicos, à geração e disseminação de informações contábeis, com reconhecido nível de precisão;

VI - Exercer suas responsabilidades com o expressivo domínio das funções contábeis, incluindo noções de atividades atuariais e de quantificações de informações financeiras, patrimoniais e governamentais, que viabilizem aos agentes econômicos e aos administradores de qualquer segmento produtivo ou institucional o pleno cumprimento de seus encargos quanto ao gerenciamento, aos controles e à prestação de contas de sua gestão perante à sociedade, gerando também informações para a tomada de decisão, organização de atitudes e construção de valores orientados para a cidadania;

VII - Desenvolver, analisar e implantar sistemas de informação contábil e de controle gerencial, revelando capacidade crítico/ analítica para avaliar as implicações organizacionais com a tecnologia da informação; 
VIII - Exercer com ética e proficiência as atribuições e prerrogativas que lhe são prescritas através da legislação específica, revelando domínios adequados aos diferentes modelos organizacionais.

Diante dessas informações, percebe-se a importância atribuída ao conjunto de habilidades, competências e conhecimentos na área contábil.

\subsection{Perfil do profissional contábil}

O profissional contábil deve ser um profissional informado e com amplo conhecimento de operações, registros, informações, entre outras, no meio empresarial para facilitar as tomadas de decisões (MARION, 2009). Além disso, serem capacitados, ampla visão, flexíveis, ágeis, comprometidos, organizados, produtivos, e que tenham conhecimentos de tecnologia e preparados para enfrentar desafios (FONSECA et al., 2014). Tobias (2010, p. 3) expõe que o profissional contábil vem sendo:

- Preparado para lidar com a tecnologia da informação que se desenvolve rapidamente;

- Capaz de compreender a complexidade das transações de negócios que ocorrem interna e externamente às empresas, para a correta mensuração do patrimônio e seu resultado; e

- Informado sobre as mudanças que ocorrem em sua profissão nos aspectos normativos e legais que influem nas atividades econômicas das entidades sob sua responsabilidade.

Tobias (2010) salienta que as empresas preferem profissional dedicados à sua profissão, que goste e tenha facilidades de leitura e de relacionamentos profissionais, inclusive interdisciplinares, que tenha uma comunicação eficaz e capacidade de entendimento do contexto de sua profissão. O profissional contábil deve ter um perfil voltado ao contínuo aperfeiçoamento pessoal em termos de capacitações profissionais, técnicas e acadêmicas (FERREIRA, 2013; SOUZA; VERGILINO, 2010).

Em suma, o profissional contábil deve ter rapidez nas soluções com clientes, trabalhar em equipe, raciocínio lógico, crítico e analítico, precisa se adaptar em diferentes situações e ter facilidade em aprender (SIVINSKI, 2009). No que se refere aos valores e atitudes, ele deve possuir responsabilidade, honestidade, ética nas questões pessoais e profissionais, busca de conhecimentos e deve ter novas ideias em relação ao trabalho e aos estudos. Quanto aos conhecimentos mais importantes que o profissional deve abranger estão: a contabilidade geral, fiscal, gerencial, legislação societária e o planejamento tributário e fiscal. 


\section{PROCEDIMENTOS METODOLÓGICOS}

\subsection{Tipo de pesquisa}

A tipificação desta pesquisa quanto a abordagem é quali-quantitativa. A qualitativa vincula-se à análise das respostas subjetivas advindas de questões abertas do questionário. Já a quantitativa foi utilizada na análise do perfil sócio-econômico. A caracterização quanto ao objetivo é descritiva, pois descreve-se o perfil dos profissionais contábeis demandado pelas empresas. Os procedimentos técnicos, por sua vez, vinculam-se a pesquisa survey por meio de um questionário misto.

\subsection{Unidade de análise}

A unidade de análise abrange as empresas que realizam a escrituração contábil interna localizadas na região do Vale do Taquari-RS. As empresas foram selecionadas de forma intencional com a tributação do lucro real, presumido e simples nacional. O convite foi realizado a 105 empresas e o contato foi realizado por telefone explicando a pesquisa e a solicitação do e-mail. As empresas que retornaram o questionário preenchido corresponderam a 43, e estas fizeram parte da pesquisa.

\subsection{Coleta, tratamento e análises dos dados}

A pesquisa survey foi aplicada em agosto de 2016 às empresas que compreenderam a unidade de análise do Vale do Taquari-RS. O questionário misto foi adaptado das pesquisas de Rua (2014) e Ferreira (2013), sendo assim, o questionário já foi validado e fundamenta uma coerência na comparação dos resultados (APÊNDICE A). Este questionário misto foi enviado por meio de email as empresas, sendo assim, sem a presença do pesquisador, onde tiveram um prazo de cinco dias para responderem e devolveram o questionário.

O tratamento de dados ocorreu com auxílio de planilhas eletrônicas do Software Microsoft Office Excel 2010. As análises das questões socioeconômicas foram realizadas por meio de gráficos de colunas. Estes gráficos foram elaborados através de planilhas com as respostas, sendo aplicado se filtros.

\section{RESULTADOS E ANÁLISES}

\subsection{Análise do perfil socioeconômico}

As questões socioeconômicas revelam que em relação ao porte das empresas pesquisadas (Q1), 51\% são optantes pelo Simples Nacional, 12\% são optantes pelo Lucro Presumido e 37\% são optantes pelo Lucro Real (GRÁFICO 
1). A análise da idade do profissional contábil desejável (Q2) revela que $60 \%$ das empresas preferem profissionais com idade entre 26 até 35 anos de idade, outros $5 \%$ até 25 anos, $19 \%$ de 36 até 45 anos e $16 \%$ não manifestaram preferências. No estudo de Ferreira (2013), 50\% das empresas preferem profissionais com idade entre 26 a 35 anos.

Gráfico 1 - Questões socioeconômicas

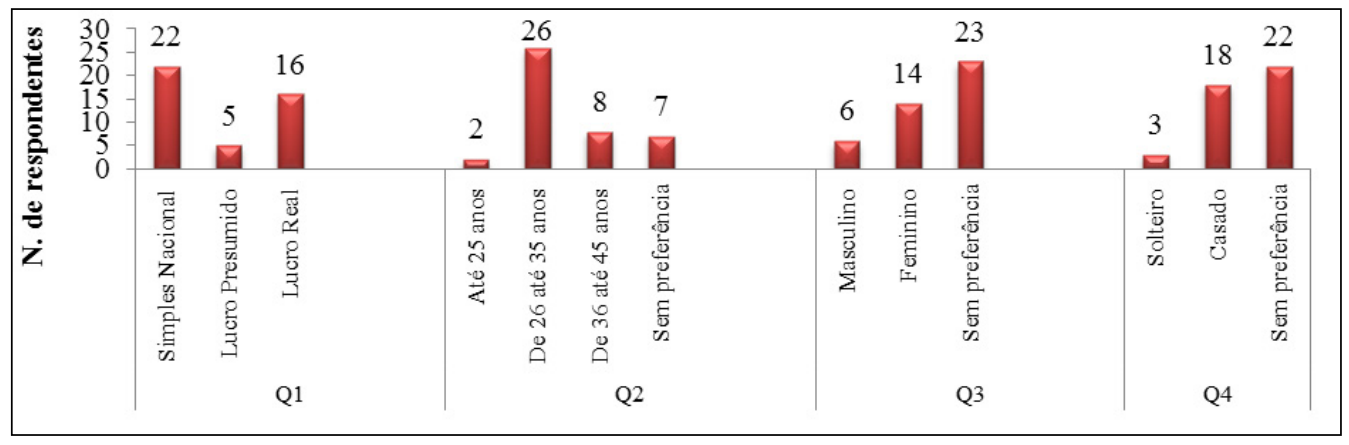

Fonte: Elaborado pelos autores.

Legenda: Q1: O porte da empresa pesquisada é? Q2: Idade do profissional contábil desejável? Q3: Gênero exigido para a vaga de profissional contábil? Q4: Estado civil dos profissionais contábeis?

As empresas, em relação ao gênero do profissional contábil (Q3), responderam não ter preferência (52\%); porém, 33\% das empresas preferem profissionais do sexo feminino e outras $14 \%$ do sexo masculino. No estudo de Ferreira (2013), com relação à amostra, o gênero feminino é preferível, entretanto, o gênero não é levado em consideração em pelo menos $75 \%$ das análises.

O estado civil dos profissionais contábeis (Q4), segundo $51 \%$ das empresas pesquisadas não tem preferência, já $42 \%$ preferem profissionais casados e 7\% delas prefere os solteiros. Rua (2014) revela que as empresas não têm preferência pelo estado civil do profissional contábil.

Na questão Q5, em relação ao tempo de experiência desejado, $44 \%$ das empresas preferem profissionais de 4 até 5 anos de experiência, para $37 \%$ das empresas deve ser de 2 até 3 anos; $9 \%$ responderam até 1 ano; e outras $9 \%$ que não têm preferência quanto ao tempo de experiência (GRÁFICO 2). Ferreira (2013) apontou que a experiência mínima de 3 anos em 38\% das vagas; já para $31 \%$ das vagas uma experiência de 1 ano já é o suficiente. Já para 19\% uma experiência de no mínimo 5 anos é exigida, o que parece ser uma exigência bem particular para o setor dada a complexidade e amplitude dos ramos da contabilidade. 
Gráfico 2 - Questões socioeconômicas

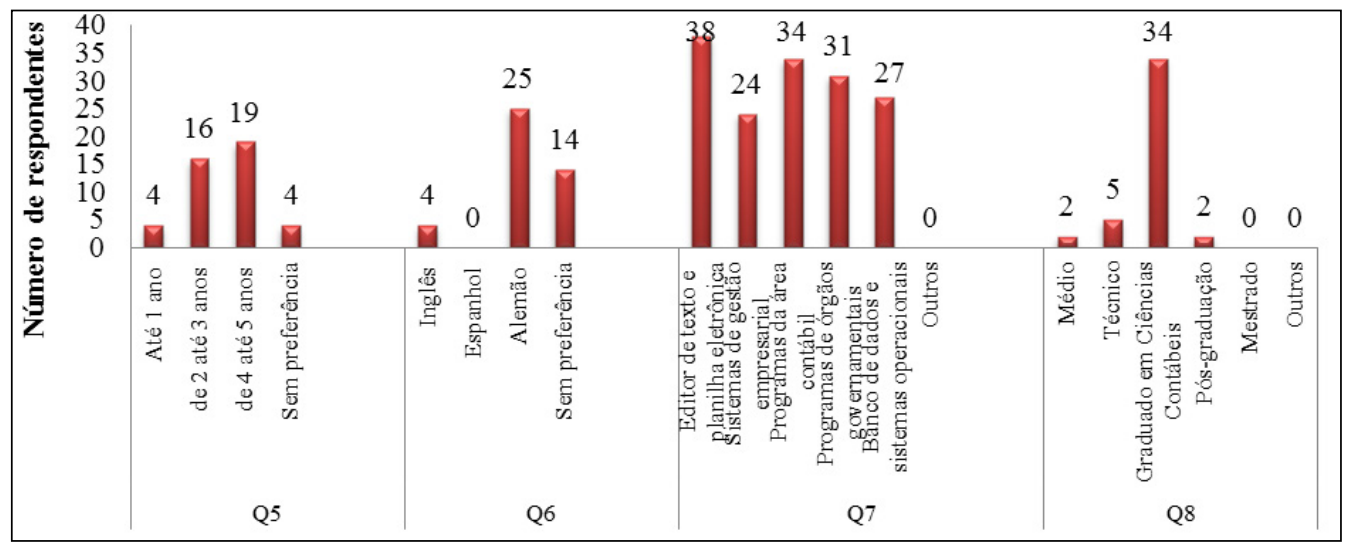

Fonte: Elaborado pelos autores.

Legenda: Q5: Tempo de experiência profissional desejável? Q6: Além da língua portuguesa, é exigido outro idioma? Q7: Quais conhecimentos deve possuir em informática? Q8: Escolaridade desejável?

A Q6 relaciona-se com a questão se além da língua portuguesa é exigido algum outro idioma e $9 \%$ dos respondentes exigem o inglês, o alemão, em função desta região ser descendente de alemães, é preferível por $58 \%$ das empresas; e 33\% das empresas não têm preferência. Ferreira (2013) revela que $87 \%$ dos entrevistados é indiferente quanto à necessidade de o candidato saber outro idioma.

As empresas necessitam de profissionais contábeis, referente à questão Q7, que possuam conhecimento na área de informática com domínio do editor de texto $(25 \%)$, dos softwares contábeis $(22 \%)$, de softwares de órgãos governamentais $(20 \%)$, de banco de dados $(17 \%)$, dos sistemas operacionais e sistemas de gestão empresarial $(17 \%)$, e dos sistemas de gestão empresarial $(15 \%)$.

Quanto ao grau de instrução (Q8), constatou-se que 12\% das empresas preferem profissionais com curso técnico em contabilidade; $5 \%$ somente ensino médio; e, para $79 \%$ a preferência é por profissionais que tenham graduação em Ciências Contábeis; ainda, outros 5\% preferem os que tenham pós-graduação. Segundo Ferreira (2013), metade das vagas ofertadas pelo mercado de trabalho exige uma especialização, $31 \%$ dos casos se faz necessário no mínimo a graduação; enquanto para 19\% das vagas oferecidas é exigida a pós-graduação.

\subsection{Questões específicas em relação ao profissional contábil}

A postura que o profissional contábil deve ter em relação as suas virtudes (Q9), o item com maior exigência relaciona-se com o trabalho em equipe (20\%); a busca por conhecimento (19\%); outras posturas observadas foram o 
conhecimento técnico (16\%); comunicação efetiva (14\%); flexibilidade $(12 \%)$; liderança (17\%); e bom humor (7\%) (GRÁFICO 3). Em comparação, o estudo de Rua (2014) reconheceu a busca por conhecimento como uma das posturas mais importantes para o profissional; e a menos importante, mas também relevante, o bom humor.

Gráfico 3 - Questões relativas ao perfil dos profissionais contábeis

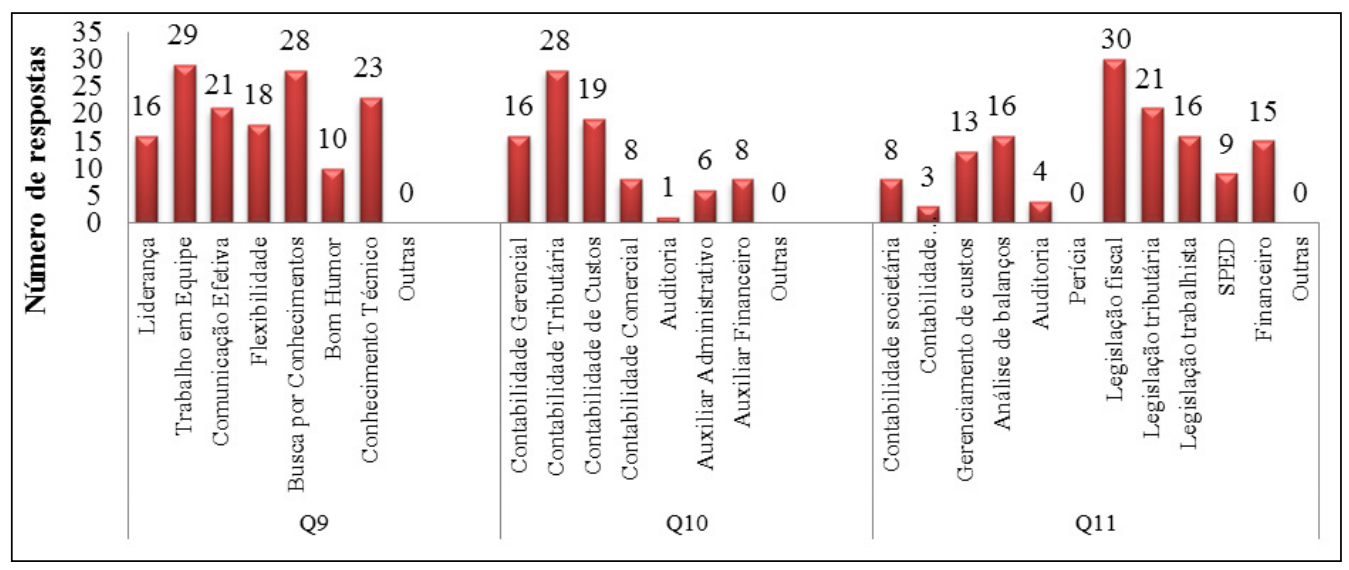

Fonte: Elaborado pelos autores.

Legenda: Q9: Postura profissional contábil exigida em relação às virtudes? Q10: Qual é o conhecimento específico sobre contabilidade que a empresa exige? Q11: Conhecimentos avançados?

A Q10 referente ao conhecimento específico mais importante, aparece em primeiro lugar a contabilidade tributária com 33\%, cujo objeto principal são os tributos. Do ponto de vista das empresas, o objetivo desta contabilidade é aplicar a legislação tributária de forma menos onerosa às entidades empresarias. Entretanto, a contabilidade de custos (22\%) e a gerencial $(19 \%)$ também são exigidas pelas empresas, assim como a contabilidade comercial $(9 \%)$, auxiliares administrativos $(7 \%)$ e a auditoria $(1 \%)$. No estudo de Rua (2014), os conhecimentos específicos considerados relevantes foram relativos à contabilidade tributária e contabilidade Gerencial; e a menos preferida também foi o conhecimento sobre auditoria.

As respostas referente a Q11 revelam que os conhecimentos avançados são preferíveis em relação à legislação fiscal $(22 \%)$, tributária $(16 \%)$, análise de balanço e a legislação trabalhista (12\%, cada área), o setor financeiro $(11 \%)$, gerenciamento de custos $(10 \%)$, conhecimento em Sistema Público de Escrituração Digital (SPED) (7\%), a contabilidade societária (6\%), a auditoria $(3 \%)$ e em relação a contabilidade internacional (2\%). Ferreira (2013) em seu estudo revela que $22 \%$ das empresas exigem conhecimento aplicado em análise de balanços e a exigência de conhecimento em contabilidade societária e gerenciamento de custos, além do conhecimento das legislações, fiscal, 
tributária e trabalhista tiveram cada uma $11 \%$. O conhecimento em auditoria foi requerido em $8 \%$, além disso, a exigência da escrituração digital $(7 \%)$, de perícia contábil é exigida em $4 \%$ das vagas e demais conhecimentos com $4 \%$.

Portanto, pode-se destacar que é imprescindível para uma fácil absorção pelo mercado de trabalho que o profissional contábil esteja familiarizado com alguns conhecimentos avançados em legislação fiscal, tributária e trabalhista, também na contabilidade societária, internacional, nos gerenciamentos de custo, análise de balanço, auditoria, financeiro e no SPED.

Na Q12 as empresas revelam em relação à área de atuação que a maior demanda centra-se na escrituração contábil (23\%) e fiscal (19\%). A apuração de impostos e análise de demonstrativos tiveram um empate com $16 \%$, a folha de pagamento e rotinas trabalhistas são exigidas em $15 \%$ e a apuração de custos (11\%) (GRÁFICO 4). Segundo Rua (2014), as áreas com mais procura foram a apuração de impostos com $22 \%$, a escrituração contábil com $21 \%$, folha de pagamento, rotinas trabalhistas e escrituração fiscal com $20 \%$, a apuração dos custos é exigida para $15 \%$ das vagas, e à análise de demonstrativos com $2 \%$.

Gráfico 4 - Questões relativas ao perfil dos profissionais contábeis

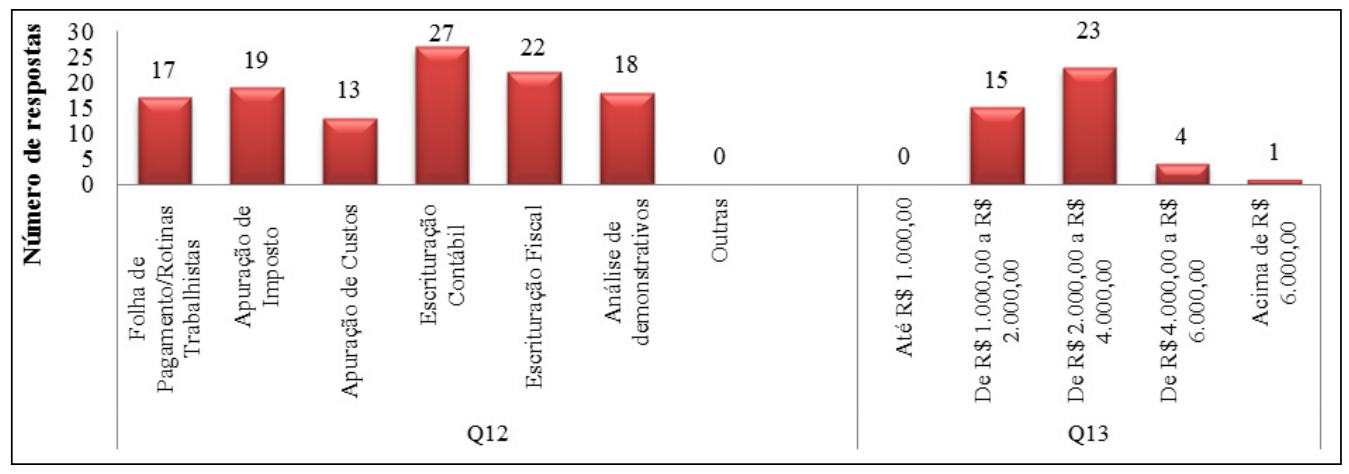

Fonte: Elaborado pelos autores.

Legenda: Q12: Área de atuação? Q13: Remuneração oferecida?

Em relação a remunerações oferecidas (Q13), 53\% das empresas oferecem uma remuneração entre $R \$ 2.000,00$ e $R \$ 4.000,00,35 \%$ entre $R \$ 1.000,00$ e $R \$$ $2.000,00,9 \%$ entre $\mathrm{R} \$ 4.000,00$ a $\mathrm{R} \$ 6.000,00$, e $2 \%$ das empresas oferecem acima de $\mathrm{R} \$ 6.000,00$. Conforme Ferreira (2013), a maioria das vagas ofertadas (63\%) oferecem uma remuneração média de $\mathrm{R} \$ 1.000,00$ a $\mathrm{R} \$ 2.000,00$, em $26 \%$ dos casos, a remuneração varia de $\mathrm{R} \$ 2.000,00$ a $\mathrm{R} \$ 6.000,00$, em $5 \%$ das empresas a remuneração oferecida para o cargo em questão é acima de $\mathrm{R} \$ 6.000,00$. 
Gráfico 5 - Questões relativas ao perfil dos profissionais contábeis

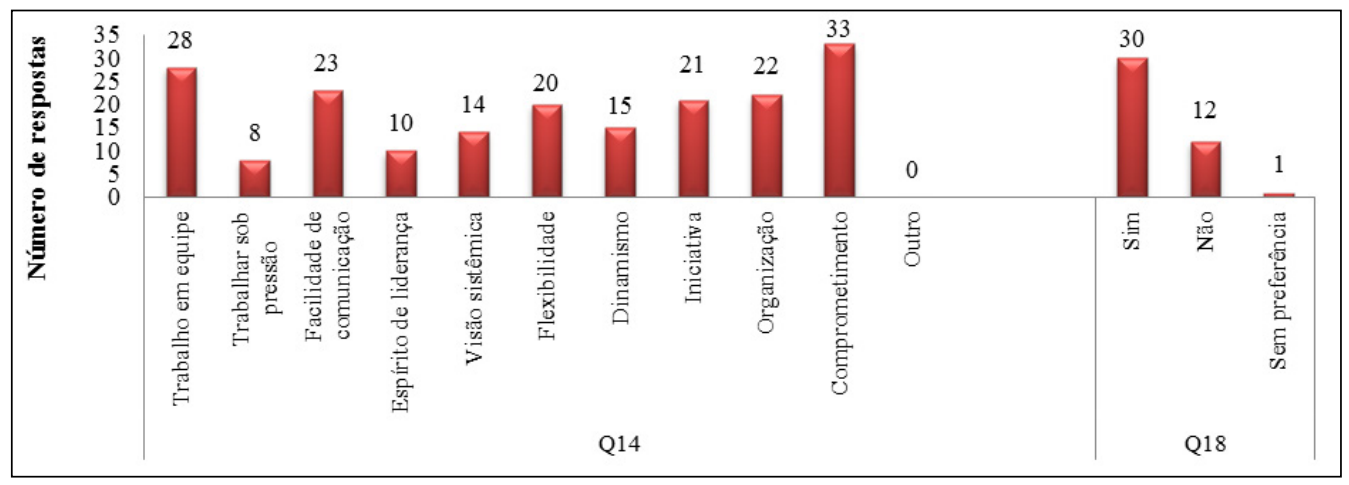

Fonte: Dados da pesquisa (2016).

Legenda: Q14: Seriam características essenciais do perfil do profissional contábil para ser contratado? Q18: Preferência por profissionais da cidade?

Conforme a Q14, o comprometimento aparece como característica essencial do perfil do profissional contábil em $17 \%$ dos entrevistados, seguido de trabalho em equipe com $14 \%$, facilidade de comunicação com $12 \%$, organização e iniciativa com $11 \%$ cada, flexibilidade com $10 \%$ das respostas. A opção de trabalhar sob pressão somente foi requisito em $4 \%$ das empresas. Cabe ressaltar a facilidade de se comunicar, aparecendo como uma característica pontual, o que vai contra os preceitos antigos referente ao profissional contábil de ser uma pessoa isolada, tímida com dificuldades de se comunicar. O dinamismo (com $8 \%$ ) e a visão sistêmica $(7 \%)$ são conceitos recentes sobre o comportamento organizacional em empresas altamente competitivas.

O estudo de Ferreira (2013) revela que o trabalho em equipe aparece como característica essencial para que o candidato esteja a contento para as vagas oferecidas pelo mercado de trabalho em pelo menos $14 \%$ dos casos. Em segundo plano aparece a iniciativa como sendo uma característica essencial (em $13 \%$ das vagas ofertadas). Outro ponto que chama a atenção é a habilidade de trabalhar sob pressão (que aparece como terceira característica com 11\%). Empatada com $10 \%$, a organização e a flexibilidade para lidar com situações difíceis e inusitadas.

De acordo com a Q18, 70\% das empresas têm preferência por profissionais contábeis que residem nos municípios onde estão localizadas. Porém, para $28 \%$ das empresas não é necessário o colaborador ser da mesma cidade e somente $2 \%$ responderam que são indiferentes à questão.

\section{CONCLUSÃO}

A partir dos resultados obtidos ficou evidente que as empresas desejam um profissional contábil de 25 até 35 anos (não fazem distinção por gênero 
e estado civil), que tenha de 4 até 5 anos de experiência e o alemão como diferencial para comunicação. Também é necessário que tenha conhecimento e domínio em editores de texto, bem como graduação em ciências contábeis. O profissional deve saber trabalhar em equipe e buscar conhecimento. Como características essenciais se destacam o comprometimento, trabalho em equipe e facilidade de comunicação.

Quanto ao conhecimento específico aparece em primeiro lugar a contabilidade tributária. Portanto, pode-se destacar que é imprescindível para uma fácil absorção pelo mercado de trabalho, que o profissional contábil esteja familiarizado com alguns conhecimentos avançados em legislação fiscal e tributária. As remunerações oferecidas ficam entre $R \$ 2.000,00$ e $R \$ 4.000,00$ e as preferências também são maiores por profissionais que residem no município onde a empresa está localizada.

Conclui-se que o profissional contábil requisitado pelo mercado de trabalho deve ter conhecimento e experiência prévia na área contábil, além disso, amplo conjunto de competências e habilidades. Como sugestão de pesquisa futura, sugere-se a comparação das demandas apresentadas neste estudo com as grades curriculares das instituições de ensino superior (IES) do Vale do Taquari - RS, indicando se os conhecimentos ministrados na formação são compatíveis com os anseios (necessidades) das empresas contratadoras.

\section{REFERÊNCIAS}

ALBERTO, Valder Luiz Palombo. Perícia contábil. São Paulo: Atlas, 1996.

BRANDALISE, Fábio; FELLA, Leonir José; ZAMIN, Leoni Menta. O Contador Público no contexto da Gestão Pública. Revista de Administração e Ciências Contábeis do IDEAU, v. 4, n. 8, p. 1-17, 2009.

BRASIL. Decreto-Lei n. 9.295, de 27 de maio de 1946. Cria o Conselho Federal de Contabilidade, define as atribuições do Contador e do Guarda-livros, e dá outras providências. Disponível em: <http://www1.cfc.org.br/uparq/decretolei_9295_1946. pdf>. Acesso em: 31 mar. 2016.

BRASIL. Resolução n ${ }^{\circ}$ 560, de 28 de outubro de 1983. Dispõe sobre as prerrogativas profissionais de que trata o artigo 25 do Decreto-lei n ${ }^{\circ} 9.295$, de 27 de maio de 1946. Disponível em: <http://www.cfc.org.br/sisweb/sre/detalhes_sre. aspx?Codigo=1983/000560>. Acesso em: 31 mar. 2016.

BRASIL. Resolução n. 10, de 16 de dezembro de 2004. Institui as Diretrizes Curriculares Nacionais para o Curso de Graduação em Ciências Contábeis, bacharelado, e dá outras providências. Disponível em: <http://portal.mec.gov.br/ cne/arquivos/pdf/rces10_04.pdf>. Acesso em: 31 mar. 2016. 
CACERE, Alex Sacilotto; CARDOSO, Juliano Damas da Silva; NORONHA, Marco Antônio Silveira. Consultoria contábil: uma nova perspectiva da profissão contábil. Portal Classe contábil, 2008.

CARDOSO, Ricardo Lopes. Competências do contador: um estudo empírico. 2006. 128p. Tese (Doutorado em Ciências Contábeis) - Faculdade de Economia e Administração e Contabilidade, Universidade de São Paulo, São Paulo, 2006.

CASNOK, Juarez; POLLI, Iracema Ribeiro Roza; POLLI, Vanilton. A formação acadêmica na área e sua contribuição para a atuação profissional: um estudo de duas IES. 2005.

CHIAVENATO, Idalberto. Administração: teoria, processo e prática. 3. ed. São Paulo: Makron Books, 2000.

CRUZ, June Alisson Westarb; ANDRICH, Emir Guimarães; SCHIER, Carlos Ubiratan da Costa. Contabilidade introdutória descomplicada. 4. ed. rev. atual. Curitiba, PR: Juruá, 2011.

DIEHL, Tania Maria. Principais métodos de avaliação de Empresas: vantagens e desvantagens. 2010. 25f. Graduação (Ciências contábeis) Universidade Federal do Rio Grande do Sul. 2010

ECKERT, Alex et al. Vantagens e desvantagens da Contabilidade Interna em relação à Contabilidade Terceirizada: um estudo multicaso. REN-Revista Escola de Negócios, v. 2, n. 1, p. 2-21, 2014.

FERNANDES, Waldir Aparecido; ANTUNES, Maria Auxiliadora. O profissional da Contabilidade: um perfil da atualidade. In: XIV ENCONTRO LATINO AMERICANO DE INICIAÇÃO CIENTÍFICA E X ENCONTRO LATINO AMERICANO DE PÓSGRADUAÇÃO. São Paulo. Anais ... São Paulo-SP. 2010.

FERREIRA, Vagner Paz. O perfil do profissional contábil exigido pelo mercado de trabalho. 2013. 59 f. Monografia (Bacharel em Ciências Contábeis). Curso de Ciências Contábeis. Universidade de Passo Fundo, Passo Fundo, RS, 2013.

FLEURY, Afonso; FLEURY, Maria Tereza Leme. Estratégias empresariais e formação de competências: um quebra-cabeça caleidoscópico da indústria brasileira. 3. ed. São Paulo: Atlas, 2001.

FONSECA, Reinaldo Aparecida et al. A Importância do Contador nas Organizações. In: XI SIMPÓSIO DE EXCELÊNCIA EM GESTÃO E TECNOLOGIA. 2014. Disponível em: <http:/ / www.aedb.br/seget/arquivos/artigos14/32720337.pdf>. Acesso em: 28 abr. 2016.

MARIN, Tany Ingrid Sagredo; LIMA, Silene Jucelino de; NOVA, Silvia Pereira de Castro Casa. Formação do Contador: o que o mercado quer, é o que ele tem? Um estudo sobre o perfil profissional dos alunos de ciências contábeis da FEA-USP.

Revista Contabilidade Vista \& Revista, v. 25, n. 2, p. 59-83, 2014. 
MARION, José Carlos. Contabilidade básica. 10. ed. São Paulo: Atlas, 2009.

PELEIAS, Ivan Ricardo. Didática do ensino da contabilidade: aplicável a outros Cursos superiores. São Paulo: Saraiva, 2006.

REIS, Anderson de Oliveira et al. Perfil do Profissional Contábil: habilidades, competências e imagem simbólica. São Paulo: 2014. Disponível em: <http:/ / www. congressousp.fipecafi.org/web/artigos142014/254.pdf>. Acesso em: 20 ago. 2016.

RODRIGUES, Ana Kátia da Silva. O Profissional Contábil e as exigências do mercado de trabalho no município de Juína. 2009. 80f. Monografia (Ciencias Contábeis) - Faculdade de Ciências Contábeis e Administração do Vale do Juruena. 2009.

RUA, Karen de Souza Patrasso. Mercado do Profissional Contábil: uma análise comparativa entre o perfil demandado pelas empresas cadastradas na FENACON e os currículos das Instituições de Ensino Superior de Brasília. 2014. 30f. Monografia (Graduação em Ciências Contábeis) Centro Universitário De Brasília - UNICEUB. 2014.

SÁ, Antônio Lopes de. Fundamentos da Contabilidade Geral. 2. ed. Curitiba: Juruá, 2006.

SILVA, Juliana Letícia Macedo. Perfil do Profissional Contábil na Gestão

Empresarial: habilidades, conhecimentos e competências a partir da percepção dos empresários de Pimenta Bueno/RO. 2015. 34f. Monografia (Graduação em Ciências Contábeis) Fundação Universidade Federal de Rondônia-UNIR, 2015.

SILVA, Manoel Dias da. Análise das perspectivas e expectativas dos acadêmicos ingressantes e concluintes do Curso de Ciências Contábeis da UNESC sobre a profissão contábil. 2012. 85f. Monografia (Graduação de Ciências Contábeis), Universidade do Extremo Sul Catarinense, UNESC. 2012.

SILVEIRA, Érica Copetti. Uma análise das competências requeridas pelo mercado de trabalho aos contadores da região da AMESC. 2013. 123f. Monografia (Graduação de Ciências Contábeis), Universidade do Extremo Sul Catarinense, UNESC. 2016.

SIVINSKI, Taís. Características mais valorizadas para os profissionais da contabilidade no Vale do Taquari. 2009. 86f. Monografia (Graduação em Ciências contábeis) Centro Universitário UNIVATES, 2009.

SOUZA, Marcos Antônio; VERGILINO, Caroline da Silva. Um Perfil do Profissional Contábil na Atualidade: estudo comparativo entre conteúdo de ensino e exigências de mercado. 2010. Disponível em: <http:/ / congressos.anpcont.org.br/congressos antigos/vi/images/epc\%2092.pdf>. Acesso em: 19 mar. 2016.

TEIXEIRA, Jéssica Mairy Alves; ALVES, Marcelo Evandro. Perfil dos Profissionais Contábeis dos Escritórios de Contabilidade de Tangará da Serra-MT. Revista UNEMAT de Contabilidade, v. 3, n. 5, p. 323-340, 2014. 
TOBIAS, Luciana Maria Michel. O perfil do profissional de Contabilidade à luz das demandas de mercado. In: XIX ENCONTRO ANUAL DE INSCRIÇÃO CIENTÍFICA, 2010. Disponível em: <http:/ / anais.unicentro.br/xixeaic/pdf/1166.pdf>. Acesso em: 18 abr. 2016.

VIEIRA, Francisco Pedro. Gestão, baseada nas competências, na ótica dos gestores, funcionários e clientes, na empresa de assistência técnica e extensão rural do estado de Rondônia-Emater, RO. 2002. Dissertação de mestrado apresentada na Universidade Federal de Santa Catarina, 2002.

\section{APÊNDICE A - Questionário de pesquisa final}

\section{PESQUISA SOBRE O PERFIL DO PROFISSIONAL CONTÁBIL REQUERIDO PELO MERCADO DE TRABALHO DO VALE DO TAQUARI}

Prezado,

Este questionário possui o objetivo de coletar informações para a elaboração do trabalho de conclusão do curso de ciências contábeis da acadêmica Ana Paula Biasibetti do centro Universitário UNIVATES. A pesquisa objetiva analisar o perfil do profissional contábil na visão das organizações. Os respondentes deste questionário serão mantidos em sigilo e as informações serão utilizadas estritamente para desenvolver o estudo acadêmico. $\mathrm{O}$ questionário foi elaborado com base em Rua (2014) e Ferreira (2013) e tem como orientador o professor e pesquisador Dr. Alexandre André Feil.

\section{PARTE I. PERFIL SOCIOECONÔMICO}

1. O porte da empresa pesquisada é:

( ) Simples Nacional

( ) Lucro Presumido

( ) Lucro Real

2. Idade do profissional contábil desejável:

( ) Até 25 anos

() De 26 até 35 anos

( ) De 36 até 45 anos

( ) Sem preferência:

3. Gênero exigido para vaga de profissionais contábeis:
( ) Masculino
( ) Feminino
( ) Sem preferência:
4. Estado civil dos profissionais contábeis:
( ) Solteiro
( ) Casado
( ) Sem preferência: 
5. Tempo de experiência profissional desejável:

() Até 1 ano
() De 2 até 3 anos
() De 4 até 5 anos
() Sem preferência:

6. Além da língua portuguesa, é exigido outro idioma?

( ) Inglês

( ) Espanhol

( ) Alemão

( ) Sem preferência:

7. Quais conhecimentos deve possuir em informática (se for o caso, marcar mais de uma alternativa)?

( ) Editor de texto e planilha eletrônica

( ) Sistemas de gestão empresarial

( ) Programas da área contábil

( ) Programas de órgãos governamentais

( ) Banco de dados e sistemas operacionais

( ) Outros:

8. Escolaridade desejável:

( ) Médio

( ) Técnico

( ) Graduado em Ciências Contábeis

( ) Pós-graduação

( ) Mestrado

( ) Outros:

\section{PARTE II. INFORMAÇÕES SOBRE O PERFIL DO PROFISSIONAL DESEJADO}

9. Postura profissional contábil exigida em relação às virtudes:

( ) Liderança

( ) Trabalho em Equipe

( ) Comunicação Efetiva

() Flexibilidade

( ) Busca por Conhecimentos

( ) Bom Humor

( ) Conhecimento Técnico

( ) Outras:

Liderança: capacidade de liderar pessoas e equipes efetivamente, desenvolvendo o seu potencial;

Trabalho em equipe: ter habilidades para realizar trabalhos em conjunto;

Comunicação Efetiva: Usar bem a comunicação, se relacionar, expressar ideias claras; 
Flexibilidade: saber lidar com mudanças, ser receptivo a elas;

Busca por Conhecimento: Profissionais que fogem da estagnação, buscando evolução;

Bom Humor: cultivar emoções positivas e ter bom humor, com uma convivência mais harmônica.

10. Qual é o conhecimento específico sobre contabilidade que a empresa exige:

( ) Contabilidade Gerencial

( ) Contabilidade Tributária

( ) Contabilidade de Custos

( ) Contabilidade Comercial

( ) Auditoria

( ) Auxiliar Administrativo

( ) Auxiliar Financeiro

( ) Outras:

11. Conhecimentos avançados:

( ) Contabilidade societária

( ) Contabilidade internacional

( ) Gerenciamento de custos

( ) Análise de balanços

( ) Auditoria

( ) Perícia

( ) Legislação fiscal

( ) Legislação tributária

( ) Legislação trabalhista

( ) SPED

( ) Financeiro

( ) Outras:

12. Área para atuação:

( ) Folha de Pagamento/Rotinas Trabalhistas

( ) Apuração de Imposto

( ) Apuração de Custos

( ) Escrituração Contábil

( ) Escrituração Fiscal

( ) Análise de demonstrativos

( ) Outras:

13. Remuneração oferecida:

( ) Até R \$1.000,00

( ) De $\mathrm{R} \$ 1.000,00$ a $\mathrm{R} \$ 2.000,00$

( ) De $\mathrm{R} \$ 2.000,00$ a $\mathrm{R} \$ 4.000,00$

( ) De $\mathrm{R} \$ 4.000,00$ a $\mathrm{R} \$ 6.000,00$

( ) Acima de R $\$ 6.000,00$ 
14. Seriam características essenciais do perfil do profissional contábil para ser contratado?
( ) Trabalho em equipe
( ) Trabalhar sob pressão
( ) Facilidade de comunicação
( ) Espírito de liderança
( ) Visão sistêmica
( ) Flexibilidade
( ) Dinamismo
( ) Iniciativa
( ) Organização
( ) Comprometimento
( ) Outro:

15. Qual é a principal dificuldade encontrada na contratação de profissionais da área contábil?

16. A empresa contrata os profissionais contábeis como auxílio interno ou como efetivamente contador externo, atuando no escritório, e prestando assessoria?

17. Descrever a atividade da empresa:

18. Preferência por profissionais contábeis da cidade:
() Sim
( ) Não
( ) Sem preferência 